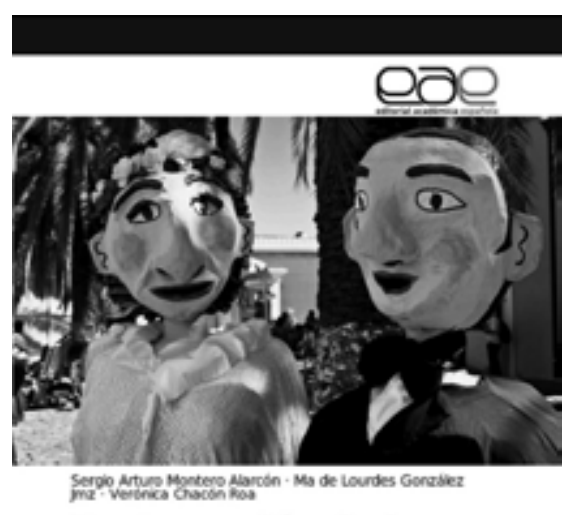

Restauración de los títeres de Rosete Aranda y época de oro del guiñol

2007 a 2008 y 2014

FIGURA 1. Portada del libro Restauración de los títeres de Rosete Aranda y época de oro del guiñol, de Sergio Arturo Montero, Lourdes González Jiménez y Verónica Chacón Roa, Saarbrücken, Editorial Académica Española, 2017, ISBN: 978-3841754769.

\section{Una representación disciplinar en tres actos: reseña del libro Restauración de los títeres de Rosete Aranda y época de oro del guiñol}

A Disciplinary Representation in Three Acts: Book review of Restauración de los títeres de Rosete Aranda y época de oro del guiñol (Restoration of Rosete Aranda's Puppetry and the Golden Age of Puppet Theater)

\author{
Alfredo Vega Cárdenas \\ Université Paris 1 Panthéon-Sorbonne, Francia \\ Alfredo.Vega-Cardenas@univ-paris1.fr
}

\section{Resumen}

Esta RESEÑA analiza Restauración de los títeres de Rosete Aranda y época de oro del guiñol (Montero, González y Chacón 2017), libro que expone el desarrollo de dos proyectos de restauración de las citadas colecciones en el título de la publicación. Examina, asimismo, los principales elementos epistemológicos de las iniciativas institucionales que dan cobijo a la investigación y restauración de las piezas, y, con base en las nociones de funcionalidad y autenticidad, estudia la forma en que ambas experiencias reflejan la dimensión interdisciplinaria de la restauración, así como los procesos cognitivos, discursivos y metodológicos del restaurador, con particular referencia al contexto de México.

\section{Palabras clave}

títeres; restauración; funcionalidad; autenticidad; interdisciplina; México

\section{Abstract}

This REVIEW analyses Restauración de los títeres de Rosete Aranda y época de oro del guinol (Restoration of Rosete Aranda's puppetry and the golden age of puppet theater, Montero, González y Chacón 2017), a book that presents the development of two restoration projects for the collections cited therein. Furthermore, it examines the main epistemological elements of the institutional initiatives that support the research and restoration of the pieces and, based on the notions of functionality and authenticity, studies the way in which both experiences reflect the interdisciplinary dimension of restoration, as well as the cognitive, discursive, and methodological processes of the restorer, with specific reference to the Mexican context.

\section{Key words}

puppetry; restoration; functionality; authenticity; interdisciplinary; Mexico 
E I libro Restauración de los títeres de Rosete Aranda y época de oro del guiñol (Montero, González y Chacón 2017) tiene su origen en los informes de dos proyectos de restauración correspondientes a las colecciones de títeres a las que se refiere el título de la publicación. La primera, la Colección Rosete Aranda, se intervino entre el 2007 y el 2009, mientras que la de la "época de oro del guiñol" ocurrió en el 2014. El profesor Sergio Arturo Montero, de la Escuela Nacional de Conservación, Restauración y Museografía (ENCRYM) del Instituto Nacional de Antropología e Historia (INAH), México, dirigió ambos proyectos.

El texto en comento consta de setenta páginas, dividido en dos secciones, que corresponden a los proyectos. La primera, que ocupa las primeras 47, está compuesta por los capítulos I al VII, y la segunda, más breve, que va de las páginas 47 a la 57, inicia en el capítulo subsecuente. Después de estas secciones, un glosario, una lista de siglas y acrónimos, una bibliografía y la síntesis curricular de los autores dan término a la obra.

Como en un eco del teatro de títeres, la reseña que el lector tiene entre sus manos reflexiona, precisamente, en tres actos en torno de los desafíos teóricos, metodológicos y logísticos de los proyectos, y analiza el alcance epistemológico de la obra.

\section{Primer acto: desde la butaca cada quien ve una historia diferente}

Por encima de una estructura propia de los informes de proyectos de restauración, esta publicación discute diferentes elementos. Sus diversos estratos de lectura se delinean de acuerdo con la butaca en la que nos instalemos, a saber:

Desde la primera fila, la obra describe la historia del teatro de títeres en México desde el siglo XIX, esto es, abunda en sus precursores, ámbitos y alcances como preámbulo a una intervención de restauración (Montero, González y Chacón 2017:10-17): desde este lugar, tal descripción histórica puede parecer rutinaria.

$\mathrm{Si}$, en cambio, estamos a la mitad de la sala, descubriremos que la misma sección relativa a la historia toca fibras del debate sobre el patrimonio. Preguntas que se han respondido ampliamente desde los estudios patrimoniales cobran aquí un nuevo sentido, con la exigencia de brindar respuestas inéditas acerca de la definición del patrimonio, de la conjunción entre materialidad e inmaterialidad o aun del carácter artificial de las fronteras entre objeto y acción.

$\mathrm{Si}$, para concluir esta visión de la ubicación en el teatro, nos situamos en las butacas del fondo, tendremos, ayudados por el distanciamiento que ofrece la profundidad, una vista de conjunto del escenario y de sus bastidores, lugar donde las entrelíneas del texto fraguan los enfoques, los argumentos teóricos, la metodología y la toma de decisiones en un proyecto de restauración. Desde aquí podemos colocar epistemológicamente los contenidos de esta publicación y entrar en el segundo acto...

\section{Segundo acto: ¿Funcionalidad versus autenticidad?}

A lo largo del libro (Montero, González y Chacón 2017:5, 33, 45, 57) la noción de funcionalidad es un elemento clave que funda la lógica e integra los criterios de intervención de uno y otro proyectos, así como también se expresa en una recuperación de la potencialidad discursiva y material de los títeres cuya finalidad consiste en que se utilicen de nuevo en espectáculos. En efecto, la perspectiva de este trabajo muestra con ímpetu el aporte hecho desde la última década del siglo pasado en la restauración mexicana acerca de la recuperación de la función de bienes culturales, como es el caso de los instrumentos musicales (cfr. Ibarra 2006) o de los bienes culturales metálicos (cfr. Cimadevilla y González 1996).

Si en la reflexión actual de la restauración la diferencia entre función y uso adquiere una relevancia singular gracias al arte contemporáneo (Cometti 2016:75-85), en el caso de las colecciones de títeres la disyuntiva se toma como un rasgo unificador tanto del objeto como del propio proyecto de restauración (Montero, González y Chacón 2017:55). Esta propuesta, que parece fincarse sólo en los aspectos prácticos de la restauración — suponiendo que en el acto restaurativo pudieran separarse la práctica y la reflexión-, en realidad constituye un evento radical de desacralización de objetos culturales $y$, por lo mismo, un pronunciamiento contra la fosilización de la cultura.

La historia del arte de la segunda mitad del siglo pasado, de la que, no sin dificultades, la restauración se ha emancipado gradualmente, nos dice, por mediación de E. H. Gombrich (1999 [1951]:4), que "el común denominador entre el símbolo y la cosa simbolizada no es la 'forma externa', sino la función". La elección de cambio de materiales y de reemplazo de algunas piezas metálicas de la colección de títeres (Montero, González y Chacón 2017:34) representa una respuesta a este dilema entre forma y función. Se abre, con ello, un terreno fértil de discusión, tanto sobre la relación dialéctica entre función y uso, como acerca de las implicaciones en torno de la noción de autenticidad respecto de la forma y la sustitución de materiales constitutivos (cfr. Eco 1999 [1997]:444-449; Ferret 1996:107-125; Hernández León 2013:171-192). De hecho, la autenticidad es un término que, en su carácter de axioma, ha provocado que corra infinidad de tinta sobre la mesa teórica de la restauración y los estudios patrimoniales.

Citamos tres puntos de vista que dan cuenta del estado de la cuestión: a) la fragua del término postautenticidad (Labadi 2010:66-84) para evidenciar los errores de objetividad asociados con la noción de autenticidad aceptada desde hace varios decenios, y para reflejar con mayor nitidez la descentralización del 
término asociada con la noción de integridad expresada en el "Documento de Nara" (ICOMOS 1994); b) los grados de autenticidad, en lugar de la visión uniforme y estática del término (Morisset 2008:23-32), y c) la autenticidad entendida como una ficción necesaria y positiva construida por el restaurador (Muñoz Viñas 2009:33-38).

En lo que toca a la presente publicación, la referida noción de autenticidad encuentra un caso ilustrativo de redefinición mediante la manera en que los autores proponen restablecer la finalidad para la que se fabricaron los títeres, es decir, su funcionalidad (Montero, González y Chacón 2017:44). Apoderados del papel de Venus en el mito de Pigmalión (Ovidio), los autores aspiran a vivificar los títeres por medio de la restauración (Montero, González y Chacón 2017:32). Lo auténtico sería, así, la justa negociación entre la continuidad y la actualización de un objeto cultural en sus diferentes dimensiones: material, significativa, discursiva y social.

\section{Tercer acto: hacia un desenlace interdisciplinario}

A lo largo de la lectura se evidencian las diferencias de abordaje y estructuración entre los dos proyectos de intervención de los títeres referidos. Mientras que el primero se concentra en el estudio de la técnica de manufactura y de los materiales constitutivos, así como en el registro fotográfico como consecuencia de la logística de la intervención (Montero, González y Chacón 2017:17-31, 36-37), el segundo da prioridad a la integración de herramientas informáticas por medio de una base de datos.

Esta, como la ha llamado su creadora, la restauradora Verónica Chacón, documentación activa presenta tres áreas de acción: 1) registro y gestión de la información visual y escrita; 2) apoyo en la configuración de una metodología de intervención para grandes colecciones, y 3) monitoreo del desempeño de los recursos humanos (Montero, González y Chacón
2017:51-52). De este modo, el paso de un registro fotográfico a una documentación activa refleja, además de la evolución disciplinar de la restauración, su traducción como consecuencia de una postura interdisciplinaria que la coloca en el meollo de una red de conocimientos y métodos (cfr. Vega Cárdenas 2012:175-192).

Aunado a ello, el libro da cuenta de las diferencias de los procesos cognitivos, discursivos y metodológicos que el restaurador emplea al momento de llevar a cabo un proyecto de restauración, de las cuales el lector encontrará buenos ejemplos. Nos ceñimos aquí a mostrar uno de ellos: en el primer proyecto, el problema de la restauración se introduce con un "contexto histórico" (Montero, González y Chacón 2017:7), mientras que, en el segundo, este apartado se define como un análisis de "los valores culturales adscritos" de la colección (Montero, González y Chacón 2017:48).

\section{Entre bastidores...}

A pesar de que la obra no ahonda en examinar las dinámicas sociales que suponen los contextos propios a las dos colecciones, trasluce la restauración como una práctica social ${ }^{1}$ (Montero, González y Chacón 2017:4850). La información generada por estos proyectos se convierte, de esta manera, en una herramienta para conocer los mecanismos de conformación cultural del espectáculo en México y de los procesos de recepción que han forjado una idea del arte popular. Con ello se hace palpable la función catalizadora de los títeres en los procesos de configuración identitaria, lo que, en términos de Krzysztof Pomian (1999:73-100), se traduce como objetos semióforos.

La publicación de esta RESEÑA nos invita, así, a revisar las actuales exigencias epistemológicas de la restau-

\footnotetext{
${ }^{1}$ La restauración como práctica social es un tema que han tratado anteriormente Eugenia Macías (2005), Alfredo Vega Cárdenas (2008) y Giovana Jaspersen (2010).
}

ración. Las cuestiones acerca de qué es una representación o qué significa la reinserción social del objeto cultural tras su intervención conducirán a una comprensión más cabal de los procesos de transmisión cultural. Al considerar los títeres como "objetos-goznes", es decir, como articuladores de procesos sociales, este libro revela las formas en que compañías teatrales como la de Rosete Aranda modelaron la cultura mexicana en la primera mitad del siglo xx. Desde ese ángulo, Sergio Montero y sus coautoras nos incitan a trascender los discursos de nomenclaturas patrimoniales desencarnadas, al afirmar que, sin su animador $y$ sin su público, los títeres dejarían de serlo (Montero, González y Chacón 2017:32). La intención de que estas colecciones se monten de nuevo manifiesta, así, el alcance ético de la restauración como un espacio de posibilidades de conformación social.

Se habría agradecido, hay que anotarlo, un mayor gasto en la edición, de tal modo que se mostraran en imágenes las diferentes etapas de la restauración y sus consecuencias materiales y visuales en las colecciones de títeres, lo que, en su ausencia, obliga al lector interesado a cotejar lo expuesto con remisión a los informes y a la base de datos, así como los artículos que sobre cada uno de los proyectos se han publicado en Intervención (cfr. Garduño 2010; Montero y Chacón 2015). De igual manera, un trabajo de este porte merecería una bibliografía unificada y más cuidada, que pusiera a la casa editorial a la altura profesional de los proyectos. No obstante, la publicación abona, entre bastidores, al esfuerzo por repensar la restauración como un terreno interdisciplinar, y se inscribe en la tarea de actualizar su arsenal terminológico y metodológico.

\section{Referencias}

Cimadevilla, Ilse y Carolusa González Tirado 1996 "La teoría de la restauración aplicada en la intervención de objetos metálicos", Imprimatura. Revista de Restauración, 12:25-33. 
Cometti, Jean-Pierre

2016 Conserver/Restaurer. L'œuvre d'art à l'époque de sa préservation technique, París, Gallimard, Collection NRF Essais.

Eco, Umberto

1999 [1997] Kant et l'ornithorynque, París, Grasset \& Fasquelle.

Garduño Ortega, Ana

2010 "Los títeres de Rosete Aranda y su restaurador: Sergio A. Montero", Intervención. Revista Internacional de Conservación, Restauración y Museología, 1 (1):39-44, documento electrónico disponibleen [http://www.scielo.org.mx/ scielo.php?script=sci_arttext\&pid=S2007249X2010000100009\&lng=es\&tlng=es], consultado en junio de 2017.

Gombrich, Ernst Hans 1999 [1951] Meditaciones sobre un caballo de juguete y otros ensayos sobre la teoría del arte, Madrid, Debate.

Ferret, Stéphane

1996 Le bateau de Thésée. Le problème de l'identité à travers le temps, París, Les Éditions de Minuit, Collection Paradoxe.

Hernández León, Juan Miguel

2013 Autenticidad y monumento. Del mito de Lázaro al de Pigmalión, Madrid, Abada Editores.

Ibarra, L.

2006 "Metodología de aproximación para la recuperación de la sonoridad de un instrumento musical. Restauración de un armonio del siglo XIX procedente del museo de arte religioso, ex convento de santa Mónica, Puebla", tesis de licenciatura en restauración de bienes muebles, México, Escuela Nacional de Conservación, Restauración y Museografía (ENCRYM).

ICOMOS

1994 "Documento de Nara sobre la autenticidad", Conferencia de Nara sobre autenticidad, Nara, Consejo Internacional de Monumentos y Sitios
(ICOMOS), documento electrónico disponible en [http://www.icomoscr.org/ doc/teoria/DOC.1994.nara.documento.sobre.autenticidad.pdf], consultado en abril de 2017.

Jaspersen García, Giovana E.

2010 “La restauración como una intervención sociocultural: herramientas y consideraciones metodológicas", tesis de licenciatura en restauración de bienes muebles, Guadalajara, Escuela de Conservación y Restauración de Occidente (ECRO).

Labadi, Sophia

2010 "World Heritage, Authenticity and Post-Authenticity: International and National Perspectives", en S. Labadi y Colin Long (eds.), Heritage and Globalisation. Key Issues in Cultural Heritage, Londres/Nueva York, Routledge, 66-84.

Macías, Eugenia

2005 Sentido social en la preservación de bienes culturales. La restauración en una comunidad rural. El caso de Yanhuitlán, Oaxaca, México, Plaza y Valdés, Serie Antropología.

Montero, Sergio Arturo, Lourdes González Jiménez y Verónica Chacón Roa

2017 Restauración de los títeres de Rosete Aranda y época de oro del guiñol. 2007 a 2008 y 2014, Saarbrücken, Editorial Académica Española.

Montero, Sergio Arturo y Verónica Chacón Roa

2015 "Restaurando el diálogo de las manos a través del arte guiñol", Intervención. Revista Internacional de Conservación, Restauración y Museología, 11 (6):3242, documento electrónico disponible en [http://www.scielo.org.mx/scielo. php? script=sci_arttext $\&$ pid $=$ S2007249X2015000100005\&lng=es\&tlng= es], consultado en junio de 2017.

Morisset, Lucie K.

2009 Des régimes d'authenticité. Essai sur la mémoire patrimoniale, Québec,
Presses Universitaires de Rennes/Presses de I'Université du Québec (PUR/ PUQ).

Muñoz Viñas, Salvador

2009 "Beyond Authenticity. The Tautological Argument and the Logic of Conservation", en Erma Hermens y Tina Fiske (eds.), Art, Conservation and Authenticities: Material, Concept, Context, Londres, Archetype Publications, 33-38.

Pomian, Krzysztof

1997 "Histoire culturelle, histoire des sémiophores", en Jean-Pierre Rioux y Jean François Sirinelli (coords.), Pour une histoire culturelle, París, Éditions du Seuil, 73-100.

\section{Ovidio}

"Pigmalión", Metamorfosis, libro x, Biblioteca Virtual Miguel de Cervantes, 243-297, documento electrónico disponible en [http://www.cervantesvirtual.com/obra-visor/metamorfosis--0/ html], consultado en abril de 2017.

Vega Cárdenas, Alfredo

2008 "El oficio de restaurador como instrumento de destino. Elementos teóricos y metodológicos para una sociología de la restauración", tesis de maestría en filosofía social, Guadalajara, Instituto Tecnológico de Estudios Superiores de Occidente (ITESO).

2012 "Tiempo de definiciones: multi, inter, transdisciplinariedad. Tres perspectivas para la conservación-restauración", en A. Gall-Ortlik y A. González (eds.), Actes de la XIII Reunió Tècnica de conservació i restauració: Interdisciplinarietat en conservació-restauració: realitat o ficció?, Barcelona, Museo Nacional de Arte de Cataluña, 175-192. 


\section{Alfredo Vega Cárdenas}

Université Paris 1 Panthéon-Sorbonne, Francia

Alfredo.Vega-Cardenas@univ-paris1.fr

Licenciado en restauración de bienes culturales (Escuela Nacional de Conservación, Restauración y Museografía [ENCRYM], Instituto Nacional de Antropología e Historia [INAH], México), maestro en filosofía social (Instituto Tecnológico de Estudios Superiores de Occidente [ITESO], Universidad Jesuita de Guadalajara, México) y maestro en conservación y restauración (Université Paris 1 Panthéon-Sorbonne [Universidad París 1 Panteón-Sorbona], Francia). Colaboró del 2000 al 2006 en la fundación de la Escuela de Conservación y Restauración de
Occidente (ECRO). De 1992 al 2006 trabajó en diversos proyectos en museos e instituciones culturales de México y, desde el último descrito, en Francia. Actualmente es corresponsable de la maestría en conservación y restauración de bienes culturales "Valor y materialidad" de la Université Paris 1 Panthéon-Sorbonne, donde imparte los cursos de introducción, epistemología e historiografía de la conservación. Es miembro del Centro Internacional de Investigaciones y Estudios Transdisciplinarios (Ciret), con sede en París, y del Comité de Conservación del Consejo Internacional de Museos (ICOM-CC). El eje de sus investigaciones gira en torno de una refundación disciplinar de la restauración. Su obra pionera sobre sociología de la restauración está en proceso de publicación por el ITESO.

Postulado/Submitted: 25.04.2017

Aceptado/Accepted: 06.06.2017

Publicado/Published: 15.06.2017

Intervención, Revista Internacional de Conservación, Restauración y Museología, año 8, número 16, julio-diciembre de 2017, se terminó de imprimir el 15 de julio de 2017, en los talleres de Calle Ciudad de México.

La edición consta de 1000 ejemplares, impresos en papel cultural ahuesado de 90 gr para interiores, y en couché de 250 gr para los forros. 